Научная статья

УДК 37.011 .33

DOI: $10.18101 / 2307-3330-2021-3-82-86$

\title{
ЕДИНСТВО ВОСПИТАНИЯ И ОБУЧЕНИЯ: СНИМАЕМ «РОЗОВЫЕ ОЧКИ»
}

\author{
(C) Халтубаева Клара Александровна \\ аспирант, \\ Бурятский государственный университет имени Доржи Банзарова \\ Россия, 670000, г. Улан-Удэ, ул. Смолина, 24а \\ cler93@mail.ru
}

\begin{abstract}
Аннотация. В данной статье рассматриваются вопросы единства воспитания и обучения, факты непонимания единства педагогической работы, необходимость наполнения ее воспитывающими, обучающими, развивающими воздействиями, недостаточная согласованность деятельности руководителей, педагогов по обеспечению единства обучения и воспитания, образования и развития детей. Для сохранения единства в образовательном процессе нужно соблюдать баланс между воспитанием, обучением, управлением и подготовкой кадров. Нехватка педагогических кадров - одна из основных проблем в школах России. Всего лишь 5,5\% от общего числа составляют педагоги 22-25 лет, до 50\% молодых педагогов уходят из школы в первые два года. Немаловажное место также занимает адаптация молодого учителя в коллективе и трудности общения с обучающимися, установление психологического контакта с учениками. Некоторые молодые учителя сталкиваются с трудностями самоорганизации и планирования своего рабочего времени и отдыха. Рассмотрены способы решения данных проблем на государственном уровне, примеры из опыта работы в образовательных учреждениях и рекомендации по решению возникающих проблем.
\end{abstract}

Ключевые слова: воспитание, обучение, молодые педагоги, образовательный процесс.

\section{Для цитирования}

Халтубаева К. А. Единство воспитания и обучения: снимаем «розовые очки» // Вестник Бурятского государственного университета. Образование. Личность. Общество. 2021. № 3. C. $82-86$.

Перед современным школьным образованием в условиях реализации ФГОС общего образования стоит главная цель: развитие творческих возможностей и способностей ребенка, сохранение как физического, так и психического его здоровья, а в конечном итоге развитие личности ребенка. В классической педагогике связь обучения и воспитания считается неразрывной, в законе об образовании понятие образование раскрывается следующим образом: «...единый целенаправленный процесс воспитания и обучения, являющийся общественно значимым благом и осуществляемый в интересах человека, семьи, общества и государства, а также совокупность приобретаемых знаний, умений, навыков, ценностных установок, опыта деятельности и компетенции определенных объема и сложности в целях интеллектуального, духовнонравственного, творческого, физического и(или) профессионального развития челове- 
ка, удовлетворения его образовательных потребностей и интересов» ${ }^{1}$. Процессы обучения и воспитания неразрывно связаны друг с другом, взаимопроникая и органично дополняя друг друга.

Роль воспитания в истории развития человеческого общества занимала особое место. В зависимости от политической и экономической ситуации в стране и мире в определенные моменты (периоды перестройки, новые реформы) основной акцент ставили на обучение. Такие перекосы в сторону обучения принесли свои плоды в виде научного прогресса, стабильного роста экономики и уровня жизни. И это хорошо!

Но не стоит забывать, что весь путь жизнедеятельности человеческого общества сопровождается воспитанием, которая является значимой частью социальной действительности.

Развитие цивилизации происходит за счет освоения опыта предыдущего поколения, его обогащения и накопления, а также дальнейшей передачи его следующим поколениям.

Усвоение научных знаний, умений и навыков осуществляется, как известно, благодаря активной работе мышления, памяти, воображения и других процессов умственной деятельности школьника. Внутренней силой, стимулирующей умственную работу, является отношение к ней: состояние заинтересованности, ответственности, радости от успеха; уверенность в достижении результата, волевое напряжение и др. Эти состояния стимулируют, направляют, регулируют познавательные процессы усвоения знаний. Вместе с тем их функционирование имеет и другое значение. Проявляясь в деятельности, они закрепляются, становятся качествами личности. Побуждения, порождаемые обстоятельствами жизни, и есть тот строительный материал, из которого складывается характер [1].

Как на самом деле обстоит ситуация в школе? Действительно ли это единый процесс воспитания и обучения? Анализ практики свидетельствует о фактах непонимания единства педагогической работы, необходимости наполнения ее воспитывающими, обучающими, развивающими воздействиями, недостаточной согласованности деятельности руководителей, педагогов по обеспечению единства обучения и воспитания, образования и развития детей. Причина этого кроется, на наш взгляд, в недостаточной педагогической подготовленности руководителей, учителей, родителей и других субъектов педагогической деятельности.

Для сохранения единства в образовательном процессе необходимо соблюдать баланс между воспитанием, обучением, управлением и подготовкой кадров.

Нехватка педагогических кадров - одна из основных проблем в школах России. Всего лишь 5,5\% от общего числа составляют педагоги 22-25 лет, и до 50\% молодых педагогов уходят из школы в первые два года. Таким образом, полноценно обеспечивать школы педагогическими кадрами становится с каждым годом сложнее. И если ситуация не поменяется, то нехватка педагогов-предметников возрастет до 188 тыс. 700 человек.

В 2015 г., когда мы получали диплом учителя физики и информатики, нам говорили: «Ваш предмет очень востребован, вас будут сразу принимать в школу. На деле

\footnotetext{
${ }^{1}$ Об образовании в Российской Федерации: федер. закон от 29.12 .2012 г. № 273-Ф3 (ред. от 02.07.2021) (с изм. и доп., вступ. в силу с 01.09.2021).
} 
оказалось совсем иначе. Вакансий учителя физики или информатики в списках Министерства образования Республики Бурятия и комитета по образованию г. Улан-Удэ не было. Не теряя надежды, я позвонила в министерство и оставила свои данные, чтобы быть в числе первых, кто претендует на вакансию учителя физики и информатики. Многие говорили, что необходимо параллельно пройти переподготовку на учителя математики, в этом случае шансы будут выше и часов будет больше.

Впоследствии устроившись в школу для адаптации детей-инвалидов, я столкнулась с неизвестным мне «надомным обучением». Сначала такая ситуация показалась очень заманчивой: обучение на дому, программа по предмету легче, проверка работ, подготовка демонстрационных материалов, ведение журнала и выставление оценок все это с одним ребенком; 6 учеников, 18 часов, нет классного руководства. В моем списке были дети с ДЦП, аутист, больной муковисцидозом, с задержкой развития. Идя к ним на урок, я не знала об этом и не имела представления, как их обучают. И уже на третий день после занятий я сидела в кабинете школьного психолога и ревела. Для меня это был огромный стресс. В университете нам об этом не рассказывали, и я не представляла, что это так тяжело эмоционально. Вместо проведения урока мне хотелось их обнять, поиграть, не хотелось ставить плохих отметок. После беседы с психологом я начала изучать литературу о том, как работать с такими детьми, корректировать программу и подбирать материалы. Стало немного легче.

Начав работать в школе, мне пришлось в период своей работы учителем столкнуться с большим объемом документальной работы: написание рабочих программ, планов уроков, заполнение журналов, подготовка отчетов каждую четверть и т. д.

С такой же ситуацией я столкнулась и в другой школе, работая там совместителем. Мне позвонили из школы-интерната, сказали, что им требуется учитель физики и информатики вместо работника, находящегося в отпуске по уходу за ребенком. Нагрузка была 12 часов, два дня работы в неделю, заведование кабинетом, выплата стимулирующих как начинающему педагогу. Прекрасный коллектив и понимающее руководство. Очень теплые отношения складывались с детьми, но для полного понимания детей нужно было больше времени проводить с ними, узнавать об их увлечениях и т. д.

Становление учителя в своей профессии происходит гораздо труднее, чем в любой другой. Для успешного становления и развития ему не хватает знаний, умений и навыков, полученных во время учебы в вузе. Хороший педагог должен быть и учителем, и консультантом, и психологом, и актером в одном лице, помогать ученику в любой момент его жизни, уметь обратить внимание на себя, пробудить интерес к тому предмету, который он преподает.

В начале своей профессиональной деятельности молодой педагог сталкивается со многими трудностями, которые учителю со стажем кажутся пустяками. Неумение грамотно рассчитать время урока, логично выстроить последовательность этапов урока, затруднения при объяснении материала, отсутствие взаимопонимания с коллегами - вот далеко не полный перечень проблем, возникающих у молодого учителя. Для него важно умение понимать себя, осознавать и умело использовать собственные резервы, грамотно определять перспективы самоопределения и самопродвижения. Прежде всего следует научиться владеть собой, правильно распределять время и усилия, постоянно заниматься самосовершенствованием и самообразованием. 
Неоценимую помощь окажут и опытные коллеги, которые так же, как и мы, когдато начинали свой путь «методом проб и ошибок». Главным помощником станет опытный наставник, которого необходимо закрепить за каждым вновь прибывшим на работу молодым специалистом.

Есть еще одна проблема, которая встречается у молодого учителя — конфликт с родителями учащихся. Молодой учитель для них не является авторитетом, учителем, обладающим способностями к воспитанию и обучению их детей, поэтому ему бывает сложно сдерживать натиск родителей, желающих посещать уроки и организовывать дисциплину.

Кроме этого, одной из основных причин ухода молодых педагогов из школы является большая нагрузка. Для получения достойной заработной платы необходимо иметь часы и классное руководство, участвовать в мероприятиях и готовить детей к конкурсам и олимпиадам (стимулирующая часть). И здесь мы наблюдаем, что все свое рабочее и свободное время учителю приходится посвящать школе: подготовка к урокам, проверка тетрадей, работа с родителями, работа с классом, прохождение курсов повышения квалификации, самоанализ своей работы и сдача отчетов.

Немаловажное место также занимают адаптация молодого учителя в коллективе и трудности в общении с обучающимися, установление психологического контакта с учениками. Некоторые молодые учителя сталкиваются с трудностями самоорганизации и планирования своего рабочего времени и отдыха. В результате ему не хватает времени на проверку тетрадей и подготовку к уроку, на выполнение других трудовых обязанностей, в связи с чем возрастает риск эмоционального выгорания, ухудшения общего самочувствия и даже потери интереса к работе.

Что же необходимо сделать для решения этих проблем? Что же делается сейчас в нашей школе Хойтобэе для поддержки молодых педагогов? Наиболее важными аспектами для адаптации молодых специалистов в педагогической среде являются постоянная поддержка и развитие профессионального потенциала педагога на этапе вхождения в профессию, правильное акцентирование требований к профессиональной деятельности начинающих учителей.

Но в первую очередь молодому учителю нужно быть готовым к разумному изменению своих личных интересов и мотивов в соответствии со статусом педагога, к работе над собой, развитию профессионально важных качеств. Открытость, естественность в общении, отсутствие страха показать себя таким, какой он есть, ощущение самого себя как уверенного, активного, способного человека - все это задает индивидуальный стиль педагога.

В школе Хойтобэе царит благоприятная атмосфера, практикуется свободный, открытый обмен мнениями, опытом. Каждый молодой педагог, пришедший в нашу школу, ощущает поддержку и понимание. Налаживается работа школы наставничества, где более квалифицированный педагог помогает менее опытному. Именно работа по выявлению и устранению проблем необходима молодым кадрам. С такой помощью молодой учитель может реализовать себя, развить не только профессиональные, но и личностные качества. Создано сообщество молодых педагогов. Составлен план работы совета молодых педагогов, который начинает реализовываться. Началась ра- 
бота школы молодого учителя. Методический совет школы проводит обучающие методические семинары по разным вопросам обучения и воспитания.

Все это в совокупности позволит молодым учителям овладеть навыками проведения и анализа урока в единстве его формы и содержания как основного фактора единства обучения и воспитания, а также под углом основных требований ФГОС.

Поэтому мои рекомендации молодым начинающим учителям: не бойтесь обращаться за советом, не пренебрегайте помощью, найдите человека, который сможет поддерживать вас в это сложное время.

Молодой педагог - это тот герой, который близок детям (возрастом и взглядами), он прекрасно ориентируется в социальных сетях и приложениях, совпадают интересы и увлечения. К нему тянутся дети. И он может влиять на происходящие изменения, но ему нужна поддержка со стороны администрации, а также оказание методической, организационной и психологической помощи.

Литература

1. Рубинштейн С. Л. Бытие и сознание. Москва, 1957. 330 с. Текст: непосредственный.

Статья поступила в редакцию 18.11.2021; одобрена после рецензирования 22.11.2021; принята к публикаиии 07.12.2021.

\title{
UNITY OF EDUCATION AND TRAINING:
}

TAKING OFF THE «ROSE-COLORED GLASSES»

\author{
Klara A. Khaltubayeva \\ Postgraduate student \\ Banzarov Buryat State University \\ 24 a Smolina St., Ulan-Ude, 670000, Russia, \\ cler93@mail.ru
}

This article discusses the issues of unity of education and training, the facts of misunderstanding of the unity of pedagogical work, the need to fill it with educating, teaching, developing influences, insufficient coordination of the activities of managers, teachers to ensure the unity of education and upbringing, education and development of children. To maintain unity in the educational process, it is necessary to maintain a balance between education, training, management and staff training. The shortage of teaching staff is one of the main problems in Russian schools. Only $5.5 \%$ of the total number are teachers aged $22-25$ and up to $50 \%$ of young teachers leave school in the first two years. Another problem is adaptation of a young teacher in a team and difficulties in communicating with students, establishing psychological contact with students, especially with difficult children. Some young teachers face difficulties in self-organization and planning their work, an important place is also occupied by the adaptation of a young teacher in a team and difficulties in communicating with students, establishing psychological contact with students, especially with difficult children. Some young teachers face difficulties in self-organization and planning their working time and rest. What methods of solving these problems are being adopted at the state level? Examples from work experience in educational institutions and recommendations for solving emerging problems are given in the article.

Keywords: education, training, young teachers, educational process.

The article was submitted 18.11.2021; approved after reviewing 22.11.2021; accepted for publication 07.12.2021. 